\title{
Diabetes Therapy
}

National Cancer Institute

\section{Source}

National Cancer Institute. Diabetes Therapy. NCI Thesaurus. Code C99532.

A therapeutic modality used to aide in the management of an individual's diabetes. 